\title{
Paternidade em Diferentes Configurações Familiares e o Desenvolvimento Emocional da Filha
}

\author{
Andressa Pin Scaglia ${ }^{1}$ \\ Fernanda Kimie Tavares Mishima-Gomes ${ }^{1}$ \\ Valéria Barbieri ${ }^{1}$ \\ ${ }^{1}$ Universidade de São Paulo, Ribeirão Preto, SP
}

\begin{abstract}
Resumo
Diante das alterações rápidas e constantes da sociedade contemporânea, observa-se um processo de redefinição/indefinição do papel paterno. Nesse sentido, objetivou-se compreender como pais inseridos em diferentes configurações familiares experimentam a função paterna, associando suas vivências ao desenvolvimento do self de suas filhas. Participaram da pesquisa oito díades pais-filhas de diferentes arranjos familiares. Foi realizada entrevista semiestruturada individual mediada por cinco cartões do Teste de Apercepção Temática Infantil (CAT-A), empregado de forma compreensiva. A estratégia metodológica foi a das "Narrativas Psicanalíticas". Os resultados apontaram que os pais demonstram, de modo singular, pouca clareza quanto aos limites e às possibilidades do exercício de suas funções e deficiências para proporcionar um ambiente suficientemente bom para as meninas, principalmente no que se refere ao oferecimento de holding. Assim, destaca-se a importância não do arranjo familiar ao qual a díade pertence, mas das posições que a criança e o pai ocupam na família.

Palavras-chave: paternidade, relações familiares, psicanálise, desenvolvimento emocional
\end{abstract}

\section{Paternity in Different Family Settings and Daughter's Emotional Development}

\begin{abstract}
In the face of rapid and constant changes in contemporary society, a process of redefinition/non-definition of the paternal role can be observed. In this sense, the objective of this study was to understand how fathers inserted in different family configurations experience the paternal function, linking their experiences to the development of their daughter's self. A total of eight father-daughter dyads participated in the research, from different family arrangements. Individual semi-structured interviews were performed, mediated by five cards of the Children's Thematic Apperception Test (CAT-A) applied comprehensively. The methodological strategy was that of the "Psychoanalytic Narratives". The results showed that the fathers demonstrated especially little clarity about the limits and possibilities of exercising their functions and deficiencies to provide a good enough environment for the girls, especially regarding the offer of "holding". In this sense, stand out the importance of the positions that child and father occupy in the family rather than the family arrangement to which the dyad belongs.

Keywords: parenthood; family relations; psychoanalysis; emotional development.
\end{abstract}

\section{Paternidad en Diferentes Configuraciones Familiares y Desarrollo Emocional de la Hija}

\section{Resumen}

Frente a los rápidos y constantes cambios en la sociedad contemporánea, se observa un proceso de redefinición/indefinición del rol paterno. En ese sentido, el objetivo de la investigación fue comprender cómo los padres, introducidos en diferentes configuraciones familiares, experimentan la función paterna, asociando sus experiencias al desarrollo del Self de sus hijas. Los participantes de la investigación fueron 8 díadas padres-hijas, de diferentes arreglos familiares. Fue realizada entrevista semiestructurada individual por medio de cinco tarjetas de Test de Apercepción Temática Infantil CAT-A utilizado de forma comprensiva. La estrategia metodológica usada fue la de las "Narrativas Psicoanalíticas". Los resultados demostraron que los padres tuvieron, de una manera singular, falta de claridad sobre los límites y las posibilidades de ejercicio de sus funciones y deficiencias para proporcionar un ambiente suficientemente bueno para las niñas, en lo que se refiere al ofrecimiento de "holding". Se destaca la importancia de las posiciones que el niño y el padre ocupan en la familia y no del arreglo familiar a la cual la díada pertenece.

Palabras-clave: paternidad; relaciones familiares; psicoanálisis; desarrollo emocional.

\section{Introdução}

A familia é fundamental para os cuidados iniciais da criança, pois oferece condições de sobrevivência, ensina normas e valores, supre necessidades afetivas e é a porta de entrada para o processo de socialização (Ferrari \& Kaloustian, 2002; Oliveira \& Camões, 2003). Assim, a interação familiar é uma espécie de prévia da maneira como irá ocorrer a relação da criança com a sociedade.
Desde o século XIX, é ressaltada a influência da família no surgimento e na manutenção de distúrbios psicológicos, destacada por Freud (1916-1917/1996) em seu conceito de "equação etiológica" ou "séries complementares". Winnicott (1960/2005) também sublinha em sua teoria o papel que a família exerce na constituição da personalidade do indivíduo, considerando que os cuidados oferecidos à criança pelo ambiente são capazes de estimular ou conter a sua tendência inata para 
o desenvolvimento. Assim, a sintomatologia da criança se relaciona com a dinâmica (psicodinâmica) familiar (Andrade, Moraes, \& Ancona-Lopes, 2014).

Embora a literatura científica sobre o desenvolvimento emocional infantil compartilhe desse pressuposto sobre a importância dos cuidados parentais no devenir da criança, a maioria tem como foco a figura da mãe, sendo poucos e recentes os trabalhos que lançam luz para a função paterna nesse processo no campo da Psicologia (Romanelli, 2003; Silva \& Piccinini, 2007). Portanto, a presente pesquisa visa contribuir com o escopo de reflexões acerca da paternidade, já que, assim como acontece no vínculo entre mãe e criança, a relação pai e filha (o) sofre constantes mudanças, pois também está sob influência da história e cultura, o que lhe confere um caráter dinâmico e plural que exige articulação/interlocução entre diversos saberes para encontrar alguma possibilidade de entendimento.

Historicamente, a ideia de paternidade, advinda da relação entre procriação e ato sexual, foi assimilada no início do período Neolítico por sociedades mais desenvolvidas (Florentino, 2002). Anterior a essa época, a organização familiar e religiosa era matrilinear, com a noção de procriação e filiação referindo-se exclusivamente ao sexo feminino. Foi necessário um longo período para o estabelecimento do sistema patrilinear; sua consolidação foi favorecida por circunstâncias históricas que destacavam atributos masculinos, tais como a guerra, que proporcionaram ao homem destaque na sociedade.

A passagem da Idade Média para a Idade Moderna foi marcada por um declínio progressivo do patriarcado que se estende até a contemporaneidade (Dupuis, 1989). Esse declínio foi intensificado e mais claramente observado no início do século XX, influenciado pelas guerras mundiais que legitimaram o trabalho feminino, bem como o movimento feminista (Amazonas \& Braga, 2006); pela interferência do Estado em diversos âmbitos, como o jurídico (leis sobre contracepção, divórcio, autoridade parental), o econômico (previdência social, aposentadoria, incentivo à poupança) e o institucional (escolarização precoce possibilitando a emancipação das mães) (Singly, 2007; Freitas, Silva, Guedes, Lucena, \& Costa, 2009).

O declínio do patriarcado promoveu uma reinserção diversificada do homem na instituição familiar. Se antes dos anos 1970 os homens eram tidos como incapazes e até mesmo inadequados biologicamente para os cuidados infantis, após essa década o papel paterno ganhou importância. Nesse contexto, a deficiência ou ausência do amor do pai não implicaria somente um mal-estar físico e emocional da criança, mas também geraria problemas comportamentais e psíquicos (Rohner, 1998). Assim, os pais são convocados para desempenhar um papel mais amplo na vida dos filhos, conforme descrito na pesquisa qualitativa de Silva, Bueno, \& Ribeiro (2014).

Assim como a reestruturação do(s) "lugar(es)" paterno(s) na sociedade, a dinamicidade da instituição familiar, principalmente nos séculos XX e XXI, também demarcou novos parâmetros nas relações de gênero e nos arranjos familiares (Simas, 2009; Amazonas \& Braga, 2006). Assistimos a uma variedade de configurações que marca uma diversificação do exercício das funções parentais (Corbin, 2008; Lobo, 2008), com a tendência para o aumento do número de famílias monoparentais e/ou reconstituídas (Oliveira, 2010). Nesse sentido, há a necessidade de compreensão mais flexível deste cenário e sua influência no desenvolvimento da criança.

Com isso, nos estudos sobre a relação entre o desenvolvimento emocional infantil e a estrutura e dinâmica familiar, é essencial entender os papéis assumidos pela paternidade e maternidade, e pelas práticas educativas privilegiadas pela sociedade e cultura a que a família pertence e pelo período histórico em que ela vive. Para tanto, a Psicanálise seria uma abordagem particularmente pertinente, tanto em termos de método como de referencial teórico interpretativo, uma vez que sua essência se constitui na busca por compreender os significados conscientes e inconscientes do comportamento humano. Mais especificamente, a teoria winnicottiana do desenvolvimento emocional pelo acento que essa abordagem coloca na qualidade do ambiente para o desenvolvimento emocional, harmônico ou não.

Winnicott (1960/2005) afirma que o desenvolvimento emocional parte de um estado de dependência total e segue para a autonomia relativa, ou seja, uma independência que não é absoluta. Os cuidados parentais dirigidos ao bebê devem acompanhar e se modificar de acordo com o estágio evolutivo por ele vivido. Assim, o pai exerceria uma diversidade de funções que acompanham o processo de desenvolvimento infantil (Fulgencio, 2007).

Em um primeiro momento, no estágio de dependência absoluta, o pai deve se apresentar como extensão da figura materna, cuidador da díade mãe -bebê (Winnicott, 1960/2005), sustentando a figura materna e o processo de criatividade primária da 
criança. No final deste primeiro momento já ocorrem falhas maternas iniciais que dão abertura para o processo de desilusão, necessário para o alcance do próximo estágio (Fulgencio, 2007).

O curso de desenvolvimento segue então para o estágio de "dependência relativa", em que se iniciam as experiências transicionais, a criatividade secundária e a simbolização. Aqui se dá a entrada do pai na vida do bebê como uma figura em si mesma (Winnicott, 1971/1975), diferente da mãe que é percebida como um modelo de integração (Fulgencio, 2007).

No terceiro estágio, rumo à independência, quando o bebê passa a ser capaz de discriminar a realidade exterior da interior, vivenciar experiências compartilhadas e desenvolver a capacidade de concernimento, o papel paterno é fundamental: o pai deve oferecer um ambiente indestrutível para a criança, a fim de possibilitar que ela experimente seus impulsos sem ser tomada por uma angústia paralisante, que ela possa testar o ambiente sem destruí-lo. Essas são as bases para importantes aquisições, como o sentimento de culpa, compadecimento e preocupação, que, aliadas às introjeções e identificações realizadas nos estágios anteriores, instrumentalizam a criança para a vivência do complexo de Édipo (Fulgencio, 2007).

Em suma, são muitas as maneiras de um pai enriquecer a vida do filho ao longo de seu desenvolvimento emocional, pois auxilia a criança em seu processo de integração da personalidade e de constituição e a continuidade do self, bem como no estabelecimento de um sentimento de continuidade de existência (Winnicott, 1955/1982).

Todos os estágios de desenvolvimento emocional caminham para a integração do indivíduo, a constituição e continuidade de seu self. Nesse sentido, Safra (2005) afirma: "compreendo self como uma organização dinâmica que possibilita a um indivíduo ser uma pessoa e ser ele mesmo. Trata-se de uma organização que acontece dentro do processo maturacional com facilitação de um meio ambiente humano. A cada etapa desse processo há uma integração cada vez mais ampla decorrente das novas experiências de vida. O "eu" seria, para mim, um campo representacional que possibilita ao indivíduo uma identidade nas dimensões do espaço e do tempo. É importante ressaltar que nem o self e nem o eu confundem-se com o ego, que é uma das instâncias intrapsíquicas de caráter funcional, articulador das demandas do id, do superego e da realidade" (Safra, 2005, p. 39). Winnicott (1958/1990) ressalta que o self é a fonte da criatividade e do gesto espontâneo.
Ele depende da estabilização dos tecidos e das funções corporais e reúne a experiência do viver do indivíduo, atribuindo-lhe uma singularidade em seu existir e a possibilidade de tornar-se um ser cultural. Para que o self se desenvolva de um estágio potencial para o total é preciso que a criança esteja inserida em um ambiente facilitador, capaz de possibilitar-lhe a aquisição de um sentimento de continuidade de existência. Assim, a principal contribuição da família é oferecer esse "ambiente suficientemente bom", que atenda às necessidades do bebê desde o nascimento, favorecendo a existência pessoal e singular. O self é que dá sentido para a ação e para o viver, desde a dependência e imaturidade até a autonomia e a capacidade de se identificar com objetos amorosos, sem perder sua identidade individual, segundo a definição proposta por Winnicott e enriquecida por Safra (2005), que será assumida também como norteadora deste estudo.

Uma vez que a constituição e a atualização do self dependem da oferta de um ambiente suficientemente bom (ou desejável médio), que é, na maioria dos casos, proporcionado pela unidade social denominada família, a compreensão do desenvolvimento do psiquismo infantil não pode ocorrer dissociada da dos pais. Se, como vimos, a figura da mãe tem sido cada vez mais considerada na empreitada de uma compreensão globalizante do filho para fins diagnósticos e/ou terapêuticos, a figura do pai permanece eclipsada por ela. Diante dessa realidade, o intuito deste trabalho é resgatar o pai em seu papel e suas funções, visto esse genitor interfere diretamente na vida da criança, em suas relações com ela, e indiretamente, por meio de sua ação na realidade psíquica da mãe. Dessa maneira, o pai, por sua presença ou ausência, física ou psicológica, além de se constituir em uma influência imediata, fornece um contexto no qual se desenrola o vínculo mãe-filho.

Todavia, se até há pouco tempo os papéis e as funções paternas e maternas eram bastante definidas, hoje se observa uma permeabilidade e interpenetração crescente entre eles, resultado das mudanças sociais, econômicas e culturais. Tais modificações, contudo, não se restringiram ao funcionamento interno do modelo da família nuclear, mas operaram e têm operado também na estrutura familiar como um todo, na legitimação de configurações como a monoparental, a reconstituída e a homoafetiva. Deve-se falar então em famílias ao invés de família, já que seus papéis e suas funções também se tornaram plurais. Desse modo, o conhecimento do que os assemelha e os especifica como pais nos diferentes arranjos familiares (e também dentro de cada um deles) 
e o impacto dessas similaridades e particularidades na constituição e no amadurecimento emocional infantil é imprescindível para uma ciência que busca compreender a formação identitária do indivíduo atual, campo reflexivo em que este trabalho se desenvolveu.

Diante das ponderações apresentadas, este estudo objetivou compreender qualitativamente o modo como pais de crianças do sexo feminino, inseridos em diferentes configurações familiares, experimentam a função paterna, associando suas vivências ao desenvolvimento do self de suas filhas, no sentido definido por Winnicott (1960/1990) e Safra (2005).

\section{Método}

Esta pesquisa foi desenvolvida no contexto de uma perspectiva epistemológica qualitativa, instrumentalizada pelo referencial teórico e metodológico psicanalítico. Assim, a ênfase foi dada ao contexto das significações conscientes e inconscientes da experiência, assumindo ainda o princípio de não separação entre os processos investigativos e interventivos, que são produzidos concomitantemente na práxis (Sander, 2002). Além disso, essa perspectiva investigativa assume uma posição de não neutralidade do pesquisador, que é valorizado na compreensão do material produzido no sentido de que suas ressonâncias afetivas, advindas do seu encontro com o sujeito investigado, são fundamentais para a compreensão do fenômeno.

Como estratégia metodológica foram utilizadas as "narrativas psicanalíticas", nas quais, após o relato do participante na situação do encontro com o pesquisador, uma narrativa é elaborada como forma de apresentar o "acontecer clínico" (Aiello-Vaisberg e Machado, 2005), ou seja, as percepções e afetações do pesquisador que possibilitam a retomada e a comunicação do encontro àqueles que não estavam presentes. $\mathrm{O}$ rigor de tal procedimento não se dá na reaplicabilidade nem na objetividade, mas na proximidade da transparência (Aiello-Vaisberg e Machado, 2004; Tachibana, Ambrosio, Follador, Beaune, \& Vaisberg, 2014; Bonfim, 2014; Barbieri, 2015).

\section{Participantes}

Participaram da pesquisa pais e suas filhas, advindos de diferentes arranjos familiares, a saber: dois pais e filhas de família monoparental materna, dois de monoparental paterna, dois nucleares, dois de famílias recompostas (sendo uma paterna e outra materna, nesta última foram entrevistados pai biológico e padrasto, que também representa uma figura parental para a criança). As crianças foram todas do sexo feminino, primogênitas, com idade entre quatro e sete anos.

\section{Instrumento}

Usou-se o CAT-A, um objeto mediador dialógico entre participante e pesquisador (Ribeiro, 2011), que faz parte da entrevista semiestruturada, sendo apenas um fio condutor, facilitador e disparador da comunicação, usado de forma compreensiva para entender como se procedia o desenvolvimento do self e não como teste psicológico. Houve a seleção de cinco dos seus cartões; as figuras de número 1, 2, 3, 4 e 8 foram escolhidas devido às temáticas latentes que evocam, referentes a situações familiares acerca de vivências de alimentação, experiência edípica, relacionamento com a autoridade, rivalidade-solidariedade fraterna e socialização, consideradas mais convenientes para os objetivos de investigar a experiência relacional entre pai e filha.

\section{Procedimentos}

Foram realizadas entrevistas individuais com os pais e, posteriormente, com suas filhas. Tanto no encontro com o pai quanto com a menina foi realizada entrevista mediada pelos cartões do CAT-A. No encontro com os pais foi feita a seguinte solicitação: "Vou the mostrar alguns quadros e gostaria que você, olhando -os, me contasse como foi e como é ser pai da (nome da criança) nessas situações". No encontro com a criança, as figuras do CAT-A foram mostradas com a solicitação de que contassem uma história a respeito de cada uma delas, dando um título ao final.

Após cada encontro com os participantes foram elaboradas narrativas psicanalíticas, devidamente interpretadas com a sinalização do que existia de comum e diferente entre as crianças em cada arranjo familiar e, em um momento posterior, foram redigidas duas sínteses de cada díade - uma de todos os pais e outra de todas as filhas, no intuito de relacionar a experiência paterna e o desenvolvimento do self das filhas, de acordo com o referencial psicanalítico winnicottiano. Neste trabalho serão apresentados os dados interpretados de acordo com as narrativas, contudo, elas não serão apresentadas. As famílias foram assim numeradas: família monoparental materna I - FMM1; família monoparental materna II - FMM2; família monoparental paterna I - FMP1; família monoparental paterna II - FMP2; família nuclear I - FN1; família nuclear II - FN2; família recomposta materna FRM; família recomposta paterna - FRP. 


\section{Resultados}

Todos os pais avaliaram a paternidade como algo positivo, mas a maioria afirmou não se tratar de uma tarefa simples. Em grande parte dos encontros com os pais, as dificuldades no exercício da função se fizeram presentes e foram atribuídas a diversos fatores, nesse sentido, o foco de alguns encontros desviou-se da relação direta com a criança e se direcionou para as dificuldades que a permeavam. Tendo em vista que os pais eram convidados a discorrer sobre a relação com a filha, sendo a pergunta disparadora da entrevista: "Como é a experiência de ser pai da (nome da filha)" e a instrução de olhar os quadros do CAT-A para basear o seu relato, na maioria dos casos pouco foi dito especificamente sobre a convivência com elas. Apresentaremos os aspectos que foram destaque durante as entrevistas em uma síntese dos pais e na sequência a de suas filhas, usando alguns subitens como guias para reflexão.

Influência Materna e a Diferença no Exercício do Papel Paterno e Materno. Todos os pais falaram que a relação com as filhas é influenciada direta ou indiretamente pela figura materna. O pai de FN1 sugere que sua esposa interfere diretamente em sua relação com a filha, situação que parece deixá-lo inseguro no exercício de sua função e pelas exigências da esposa, que confunde limite com agressividade: "[...] quando sou um pouco mais áspero, é porque minha filha é muito teimosa, acho que como toda criança. Minha esposa teve uma vida muito complicada em relação ao pai dela, por isso quando sou um pouco mais áspero com nossa filha ela acha que eu estou me excedendo. Isso me deixa preocupado, chateado e confuso às vezes [...]". O mesmo pai, diante da figura do CAT-A que mostra um leão sentado no trono, prontamente verbaliza: [...] Seria eu lá na minha poltrona, quem manda sou eu, tudo do meu jeito para a coisa não ficar feia. Mas comigo não é assim, eu tenho uma poltrona na sala, mas não é cativa, todos ocupam o meu lugar [...]".

Os pais de arranjo FMP1 e FMP2 apresentaram relatos similares, ambos são viúvos e principais cuidadores das filhas. A influência materna é marcada pela ausência, e a falta funciona como parâmetro/comparação. Eles assinalaram que o falecimento de suas esposas fez com que eles assumissem novas tarefas/cuidados, que antes eram tidas como responsabilidade das mulheres, antes mesmo de elaborarem o luto. O pai FMP1 exemplifica: "[...] final de semana eu não gosto muito de sair, não gosto de ir ao shopping. Nisso eu acho que sou falho porque minha esposa os levava. Ela faz falta [...]".
Os pais de FMM1 e o pai biológico da FRM declararam um conflito com a mãe biológica, afirmando que a mãe busca separar a filha deles, muitas vezes sem poupá-las da disputa. Assim, a dificuldade em estabelecer uma relação mais próxima com as filhas, segundo eles, se dá pela dificuldade de contato com a mãe biológica das crianças. O pai da FRM, ao se deparar com a figura do "cabo de guerra", fala sobre a disputa entre a mãe da criança: "[...] Cabo de guerra em relação a minha filha e a mãe. Às vezes eles colocam muita coisa na cabeça da menina, tem dias que eu falo para ela ir em casa e eles não deixam. Eu ameaço entrar na justiça para conseguir a guarda. Às vezes elas querem complicar minha vida".

Os pais (exceto os da FRM e o de FMP1) ressaltaram a diferença que entendem entre o papel materno e paterno no cuidado da filha, atribuindo ao pai uma atitude de imposição de autoridade e à mãe uma atitude afetuosa. Contudo, destacaram a necessidade de oferecer para as filhas tanto autoridade quanto afeto. $\mathrm{O}$ pai da FMP I afirma que após o falecimento da esposa ocorreu grande mudança na relação com os filhos: “[...] mudou porque era assim, a mãe permitia mais coisas, eles ficavam mais à vontade com ela. Eu deixava ela lidar mais com as crianças do que eu, eu participava só quando precisava. Agora eu tive que fazer o papel dela, a adaptação foi complicada. Eu assumi o papel dela só que mais rígido. Eles tiveram que buscar em mim um pouco dela. Eu dou ordem, tem que fazer, sou desse jeito. Ela era mais sensível, eu não sou”.

Os pais apresentaram estratégias e prioridades distintas na educação de suas filhas. Alguns se mostram ausentes, como expectadores, atribuindo à mãe a maior responsabilidade. Nesse ponto os relatos do pai e do padrasto da FRM e o do pai FMM1 são particularmente elucidativos. O padrasto da FRM afirma que a criança possui "um lado feroz e outro dócil" e quem lida é a mãe, ele é mero observador. O pai de FN1 demonstra que o controle que a esposa exerce sobre as relações familiares dificulta a clareza do seu papel que se modifica diante da demanda não da filha, mas da esposa. Os outros pais, apesar de se considerarem mais próximos, demonstraram uma busca por suprir prioritariamente as necessidades materiais de suas filhas e não afetivas, atendendo seus desejos de consumo material. O pai de FRP afirma que está com a filha por ter melhores condições financeiras e complementa: "[...] domingo era dia que a gente passeava, ia no shopping. Ela tem muitos brinquedos em casa, bicicleta. Sempre gostou de ficar mais comigo". Apesar de todas as esposas ou mães biológicas trabalharem, exceto a ex-mulher (falecida) da 
FMP1, somente o pai de FRP relatou ajudar nas atividades domésticas.

Qual é o Meu Lugar como Pai? Os pais se mostraram confusos no exercício da paternidade por diversas razões: sobrecarga e necessidade de suprir muitas demandas novas que os deixam distanciados da reflexão, fazendo-os agir de distintas maneiras para se apropriar de um lugar, mesmo que ainda não definido (FMP1 e FMP2); o exercício da função é baseado no medo em perder o afeto da filha, assim é ela quem cadencia as ações do pai, dominando-o (FN2). O pai FMM I e pai e padrasto FRM mostraram-se ausentes e distanciados, e demonstraram dificuldade em estabelecer uma relação de maior envolvimento e proximidade.

Os pais de FMP1 e FMP2 destacam a importância de apresentar uma postura de autoridade e consistência. Por outro lado, o pai FN2 visa proteger a filha do mundo, fazendo uso de ameaças, chantagens e recompensas, conforme ilustrado em sua fala: "Por exemplo, ela não gosta de colocar cinto de segurança na cadeirinha, então a gente tem que falar: 'olha, a polícia vai pegar!', daí ela coloca".

Os pais de FMP descreveram relação mais próxima com suas filhas, mas também foram mais críticos em relação aos limites e às possibilidades na maneira como vivenciam a paternidade. O pai de FMP1 I afirmou notar as necessidades da filha que não era capaz de suprir, pois se sentia falho no provimento de afeto. Por outro lado, os pais mais distanciados (FMM1 e FRP) descreveram suas funções de maneira muito positiva e idealizada, o que prejudicou a percepção da limitação de seus papéis e das reais demandas de suas filhas. Assim, indicam não possuírem clareza sobre o lugar que ocupam na relação.

Valorização da Família. A maioria demonstrou contar com o apoio de membros da família extensa no cuidado com a filha, destaque para pais de FMP que ressaltam principalmente a função dos avós. Todos os pais valorizaram a família nuclear, tendo-a como referência de ideal: houve condenação ao divórcio (FN1); referência, com muita saudade, do tempo em que contava com a presença da esposa no lar (FMP1) e estava inserido em família nuclear; busca por reatar o namoro quando soube que a mãe de sua filha estava grávida (FMM2) para oferecer à filha família nuclear; referência à família nuclear como "o caminho certo" e culpa por ter dificuldade em incluir a filha na nova família (FMM1); revelação de que sustentou um casamento fracassado por acreditar que aquela constituição seria a melhor para a sua filha (FRP).
Contudo, os pais que constituíram uma nova família descreveram a relação das filhas com as atuais esposas como muito agradável, apresentada de maneira idealizada como mais valiosa até do que com a mãe biológica. Além disso, eles revelaram que possuem relações diferenciadas com seus filhos e com os enteados. O pai de FMM1 assumiu possuir maior proximidade com seu filho biológico, com quem coabita, do que com a filha que está na casa dos avós. O padrasto FRM entende e exerce seu papel de maneira limitada com a justificativa de que não é pai biológico.

Síntese Filhas. A maneira direta como as filhas descreveram seus pais ao longo do encontro sugere o tipo de relacionamento existente. A de FMM1 demonstrou não possuir uma descrição clara de seu pai: ele foi mostrado por ela de maneira confusa, ambivalente e distante. A de FMM2 sugeriu que o suprimento que seu pai oferece não coincide com as suas necessidades. A de FN1 discorreu sobre o contato que tem com seu pai, parecendo valorizar a presença e a proximidade, mesmo que o pai estivesse envolvido em outras tarefas, principalmente relacionadas à mãe. A criança da FRP, em diversos momentos, ressaltou a importância do "ter" e, ao citar a figura paterna, relacionou-a com a compra de objetos, demonstrando valorizar o que o pai pode lhe dar materialmente. Quando foi solicitado à criança que contasse uma história, ela avistou uma garrafa com o emblema de sua escola dentro de um armário e respondeu ao pedido de maneira a solicitar uma troca material: "Eu preciso de uma garrafinha da escola, eu não tenho. Eu preciso!".

No entanto, a referência paterna não pode ser reduzida somente ao que foi dito diretamente. Assim, ao incluir o conteúdo latente das histórias, os pais ganharam diversos significados nos relatos das filhas. Elas descreveram a figura paterna como inconstante, dominada, com falhas no suprimento afetivo, pouco autoritária e distanciada. Para a garota de FN1, o pai representava ora refúgio, ora autonomia, no entanto tais representações parecem se alternar não em função das necessidades da garota, mas sim do pai; ressalta-se que se trata de uma relação fortemente marcada pela presença materna, que a determina. Nas histórias da criança de FN2, o pai aparece como alguém que é dominado por ela: ao falar dos personagens do cartão 2, ela diz: "Não irrite a mulher ursa! [...] Tem ursos puxando a corda, a mulher ursa está brava e disse para o urso não irritá-la". Durante toda entrevista a criança apresentou pouca tolerância e necessidade de domínio, em diversos momentos sua fala apresentou o tom de imposição e 
autoridade tais como "espere lá fora!", “agora chega, vamos embora!".

Nas histórias apresentadas, a criança de FMP1 descreveu seu pai relacionado, principalmente, aos cuidados concretos, como o provedor de segurança e proteção da família, mas também alguém a quem ela, por vezes, podia dominar. A de FMP2 indicou que o pai representava uma figura de autoridade coerente com quem se preocupa e de quem não exige muito. A de FRP manteve a imagem de seu pai relacionada com a provisão material; já a da FRM não apresentou o pai e nem o padrasto como figuras de autoridade, capazes de lhe oferecer delimitação e segurança. A de FMM1 demonstrou distanciamento desta figura em sua vida e a de FMM2 apresentou o pai em suas histórias como alguém que impõe limitações, não atende suas necessidades e tem atitude contrária às que ela entende como corretas.

Diante do exposto, a maioria das participantes, independentemente do arranjo ao qual pertencem, demonstrou que estão inseridas em um ambiente pouco estável e seguro, o que parece dificultar a vivência da transicionalidade. Os pais não foram descritos pelas filhas como modelos de força, consistência e segurança. Ao contrário, foram entendidos, por vezes, como frágeis ou distantes. As meninas percebem o exercício da função paterna com pouca clareza e consistência, com dificuldade no suprimento das demandas afetivas. Mesmo quando próximos indicam que não estão atentos às suas demandas, que muitas vezes pareceram ser alvo de projeções paternas. Contudo, as filhas provenientes de FMP1 e FMP2 apresentaram alguns pontos divergentes das demais, pois demonstraram possuir uma relação mais autêntica com seus pais. A relação entre as díades deste arranjo passou por um rico processo de reconstrução diante da ausência materna.

\section{Discussão}

A sociedade contemporânea marca um conflito nas relações humanas: apesar dos laços entre os indivíduos serem cada vez mais frouxos e solúveis, há uma busca constante por referências sólidas, como as proporcionadas pelas relações familiares (Bauman, 2004). Assim, trata-se de uma instituição valorizada, sendo que aqueles que antes a repudiavam, vêm aderindo e lutando pela integração e igualdade de direitos entre os diversos tipos de família da atualidade (Roudinesco, 2003). Ainda, observa-se uma maior mobilidade conjugal (Singly, 2007) e o fato de a família ter se tornado plural em seus arranjos, o que possibilita abarcar uma diversidade de relações estabelecidas em seu interior e entre ela e outras instituições sociais.

A pluralidade da família é consequência de mudanças nas relações de gênero e da diferenciada relação entre "a autonomia individual e o pertencimento familiar", decorrentes de diversos acontecimentos, como a entrada da mulher no mercado de trabalho, o surgimento e aperfeiçoamento dos métodos contraceptivos, o divórcio, entre outros.

Apesar dessas novas possibilidades, a valorização do arranjo nuclear se fez presente na maioria das entrevistas realizadas com os genitores. Pais inseridos ou não em configurações familiares nucleares descreveram esse arranjo como "correto" e desejado. Porém, a todo o momento, os pais também demonstraram vivenciar "crises de referências simbólicas" diante das constantes mudanças que pedem releituras sobre o mundo. Assim, as novas configurações familiares, por representarem algo distanciado da "correta" família nuclear, são ainda apreendidas como ameaçadoras.

Embora a valoração pelos pais da configuração familiar nuclear pudesse estar vinculada a uma concepção de que ela proporcionaria uma maior definição nos papéis de seus membros, a clareza na discriminação desses papéis não foi referida diretamente nas entrevistas realizadas com os pais provenientes de famílias com esses arranjos. Ao contrário, estes pais se sentem inconsistentes e ambivalentes diante do exercício de sua função. Mais uma vez, a família nuclear tradicional parece corresponder a um ideal de organização presente nos indivíduos inseridos em outros arranjos, que não se aproxima do que é realmente vivenciado por quem faz parte dela. Assim, apesar dos pais terem indicado uma ampliação nas responsabilidades relacionadas a seus filhos, eles mantêm a hegemonia do modelo patriarcal como principal referência (Freitas, 2008).

Da mesma maneira, em todos os arranjos familiares, os pais entrevistados se mostraram confusos diante do que pareciam entender como exigências "antigas" e "novas" de seu papel. Ao mesmo tempo em que diferenciaram o papel paterno do materno, sendo o primeiro descrito como mais vinculado ao exercício da autoridade e o segundo mais à provisão do afeto, sentiram-se exigidos (exceto os de FMM1 e FMM2 e o pai biológico e padrasto da FRM) para desempenhar ambas as funções, Nesse sentido, alguns dos pais tentaram transmitir uma imagem de alguém que desempenhava o seu papel e exercia suas funções de maneira mais tradicional, coerente com o que eles entendiam acerca do 
que um pai deveria fazer, o que os impedia de apresentar um olhar mais crítico para o papel e a função em si mesmos. Tal indefinição corrobora a problematização de Silva (2007) quando coloca que, apesar das mudanças ocorridas no papel paterno nas últimas décadas, ainda é incipiente o conhecimento sobre como tais mudanças refletem na rotina dos pais e na percepção do exercício real da função.

Os pais que participaram desta pesquisa, na tentativa de se descreverem de maneira menos pautada em seus atributos reais do que ideais, atribuíram a si mesmos características que entendiam como mais compatíveis com o papel tradicional do pai, vistas por eles como as mais adequadas. Esse intento, contudo, não se sustentava por muito tempo e as contradições nos relatos logo apareciam. Nos pais entrevistados, não é o "sentido relacional" que parece reger as relações com suas filhas. Ao contrário, o vínculo biológico é o que foi mais valorizado. No sentido de valorização dos laços de sangue e diante da ausência/afastamento da mãe, no caso das FMP1 e FMP2 e FRP com a guarda da criança, alguns dos pais entrevistados optaram por pedir ajuda para cuidar da filha para outras pessoas pertencentes à família extensa, mais especificamente para a avó (mãe do pai). Assim, diante da falta materna, é outra figura feminina que media o contato do pai com a filha, com a figura da mãe sendo deslocada para a avó, no caso, ou diluída para outras figuras femininas.

Apesar de todas as esposas possuírem trabalho remunerado, somente um dos entrevistados afirmou ajudar nas tarefas domésticas, situação que mostra mais uma vez a oscilação entre o "novo" e "antigo" em nossa sociedade. Portanto, as entrevistas reiteram que as modificações na esfera familiar não estão sendo ainda acompanhadas por mudanças culturais mais amplas, mesmo nos pais de novas configurações familiares. Assim, eles buscam uma adequação ao que acreditam que o ambiente exige, porém, não há clareza sobre tais exigências e, mesmo quando a clareza existe, a sua aclimatação a elas é incompleta (Thorne, 1992).

A falta de clareza intensifica-se diante da dificuldade para estabelecer um contato real/íntimo entre as díades, o que parece ser sustentado pela dinâmica da sociedade pós-moderna. Girola (2004) aponta a rapidez no consumo e a supervalorização de bens na contemporaneidade como gatilhos para uma intensificação do processo de qualificação e necessidade constante de requalificação das competências para o trabalho. Ao mesmo tempo, o mundo virtual facilita a disseminação de uma torrente de símbolos vazios em significados. Nesse contexto, o mundo acelerado e descartável influencia o modo de pensar do indivíduo que percebe seu entorno como inconstante e provisório. Assim, a lógica da sociedade contemporânea apresenta um ambiente que invade, esvazia, priva o homem de seu desejo e o distancia do outro.

Tais considerações sobre o posicionamento do homem contemporâneo são de grande relevância para a Psicanálise. Segundo Aiello-Vaisberg (2004), as práticas em Psicanálise devem ir ao encontro da ética desta corrente do saber, que considera a articulação entre o homem como um ser social, que tem suas relações influenciadas por seu tempo histórico, e seu lugar social, demográfico, familiar. A teoria winnicottiana é expressivamente pautada pela experiência e pelo ambiente integrado por pessoas reais que nele estabelecem relações que possibilitam que o bebê experiencie o real. Assim, a criança não se constitui somente pela fantasia, mas pelo manejo real dos pais diante do cuidado oferecido a ela e em seu desenvolvimento emocional (Winnicott, 1960/2005). A qualidade das relações atuais é circunscrita não pelo "ser", mas pelo "produzir". Assim, segundo Girola (2004), é difícil estabelecer um self individual, pois este emerge da vivência de uma relação:

"não abstrata com o meio ambiente, mas numa relação pessoal, marcada pelo amor, pela capacidade do meio ambiente conter o individuo e interagir com ele de forma adequada, no respeito de sua criatividade originária e única. Um meio ambiente que não seja invasivo, que saiba respeitar o devaneio e o brincar" (Girola, 2004, p. 143).

Girola (2004) ainda assinala que a sociedade pósmoderna oferece um ambiente bastante distanciado daquele entendido por Winnicott como suficientemente bom. Trata-se de um ambiente intrusivo, ameaçador, efêmero, que esvazia o indivíduo de sentido e, assim, dificulta a constituição/vivência de um self verdadeiro. Nesse sentido, o falso self surge como uma defesa diante de um ambiente que pouco favorece a espontaneidade e a autenticidade, impedindo que o "si-mesmo" seja expresso, revelado (Abram, 2000).

Os pais participantes dessa pesquisa também são marcados pelo tempo histórico e, com isso, demonstraram dificuldade para oferecer um ambiente suficientemente bom para suas filhas, principalmente no que se refere ao oferecimento de holding, um entrave para a continuidade do self das meninas. Essa conclusão é sustentada pelos relatos da maioria das filhas, quando expressaram estarem inseridas em um ambiente pouco 
acolhedor, independentemente do arranjo familiar. Ainda, elas referem dispor de uma relação distante com seus pais, sentem que eles não as percebem de maneira real e não sustentam suas fantasias. Os pais parecem não atuar como facilitadores da vivência da transicionalidade de suas filhas, o que compromete a expressão do gesto criativo; essa situação foi mais evidente nas meninas procedentes de arranjos monoparentais maternos, em que os pais se encontram mais distanciados.

Essa questão face à vivência das experiências transicionais foi também sustentada pela dificuldade dos pais de impor limites à criança, situação que apareceu principalmente nas FRP, FN1 e FN2. Nesses casos, os relatos das crianças evidenciaram uma grande dificuldade dos pais para frustrarem-nas, mantendo-as em uma atitude onipotente diante do mundo. Nesse sentido, a impossibilidade de ouvir "não" compromete a aquisição de importantes conquistas na etapa da dependência relativa. Rosa (2011) apresenta uma divisão em três momentos da função da fase do "não" para Winnicott: no primeiro, o "não" materno é direcionado somente ao mundo externo; no segundo, é direcionado à criança; no terceiro, já constitui parte da ética da criança. Quando direcionado à criança, ele representa um sinal do pai em sua vida: trata-se de "aspectos paternos nos cuidados da mãe, que se referem, inicialmente, a elementos mais rígidos da mãe, sustentados com certa firmeza.

Winnicott (1958/1990) afirma que a função paterna e materna se somam em cada estágio do desenvolvimento. Contudo, os pais participantes desta pesquisa, exceto os de FMP, ressaltaram que vivenciam dificuldades na complementariedade dos papéis e que muitas vezes é a mãe quem assume o papel de cuidado. Os pais de FMP, apesar das dificuldades, conseguem estruturar uma relação mais próxima com as filhas em comparação com os pais provenientes de outras configurações familiares. Diante do falecimento da esposa, eles precisaram repensar suas funções e acabaram por se apropriar da função paterna, e não da materna. Desempenharam seu papel de uma maneira próxima, com clareza diante de seus limites e de suas possibilidades, e conservaram uma imagem muito positiva de suas esposas. Segundo Dias (2003), diante da morte do pai, é de grande relevância a maneira como ele foi representado na realidade interna materna. Os relatos destes pais permitem afirmar que a mesma conclusão pode se aplicar nesses casos em que houve o falecimento materno, pois os pais mantiveram essa imagem positiva da esposa, que consolidava a experiência positiva vivida pelas meninas com a mãe. A figura materna, mesmo ausente, permanece como facilitadora do desenvolvimento emocional da menina.

Os relatos das crianças permitiram concluir que todas elas vivenciavam experiências referentes ao estágio do concernimento; todavia, a maioria não demonstrou atribuir ao pai características importantes para a vivência deste período, tais como força, consistência, segurança. Ao contrário, a maioria dos pais foi percebido pelas filhas como distantes, ambivalentes, inconsistentes, com pouca espontaneidade e com dificuldade para frustrar. Com isso, as meninas demonstraram que não se sentem seguras para experimentar seus impulsos destrutivos. $\mathrm{O}$ pai, quando percebido como forte e protetor, faz com que a criança não tema destruir a mãe com seus impulsos não integrados. Assim, não há necessidade de inibir os impulsos e sentimentos dessa fase do desenvolvimento, importante para a aquisição do sentimento de culpa, sofrimento e reparação (Winnicott, 1958/1990).

A dificuldade dos pais de possibilitar essa experiência para a filha parece se relacionar com uma questão pessoal na própria vivência desta fase. Sentimentos como culpa, sofrimento e reparação não estavam presentes no encontro com a maioria dos pais. Houve uma significativa dificuldade de aproximação real e não idealizada dos pais com suas filhas, uma vez que o papel paterno demonstrou ser demarcado de maneira prévia, o que os distancia do sentido relacional (Motta, 2006) e do exercício da empatia. A ênfase que os pais atribuíram às demandas concretas, por vezes para se afastar de questões com teor subjetivo, parecem não atuar como facilitadoras para que ocorra a integração das pulsões do self das crianças.

Segundo Winnicott (1945/2000) o crescimento dos filhos é um processo que desafia os pais para a necessidade de dar continuidade ao seu próprio desenvolvimento. Os pais demonstraram pouca clareza sobre o lugar que ocupam na relação com as filhas, independentemente do arranjo em que se enquadram. A indefinição sobre o papel paterno esteve presente em todas as entrevistas, mesmo que remetendo a momentos passados, como no caso das famílias monoparentais paternas. O prejuízo se acentua pelo fato de que há dificuldade de que a relação seja criada na vivência do dia a dia, já que os pais demonstraram se moldar a ideais pré-estabelecidas. Assim, parece haver um sentimento de não pertencimento e um recorrente afastamento que traz a constante percepção de necessidade de inserção. As reais demandas de suas filhas, mesmo quando percebidas, parecem ficar em segundo plano. 
Essa dificuldade no exercício da paternidade faz com que as meninas também tenham prejuízo na expressão do verdadeiro self, muitas vezes enfrentando problemas ao agir no mundo de maneira espontânea e criativa, apegando-se ao que é concreto e real. Nos casos dos pais provenientes de famílias recompostas (FRM e FRP), verificou-se uma complicação da parte deles para incluir de fato as filhas em suas novas vidas e famílias. Já os pais que possuem uma visão menos ideal e mais fiel ao exercício da própria função, como os de família monoparental paterna que expressam seus limites, demonstraram se empenhar em fornecer consistência e segurança para suas filhas. Em muitos casos, obstáculos próprios dos pais atravessavam o relacionamento com suas filhas e se traduziam em atitudes, tais como a dificuldade em frustrar e o excesso no provimento afetivo; o que também comprometia o suprimento às demandas reais das crianças.

Assim, com exceção dos pais provenientes de FMP1 e FMP2, que demonstraram maior clareza quanto aos limites e às possibilidades do exercício de suas funções, os pais dos demais arranjos demonstraram restrição em estabelecer contato com as filhas de maneira autêntica, por vezes distanciada e, quando próxima, apresenta-se de forma idealizada, além de não conseguirem oferecer um ambiente seguro e acolhedor para suas filhas.

\section{Considerações Finais}

Esses resultados demonstram a relevância da função paterna para o desenvolvimento emocional infantil. Mudam os arranjos, mas algumas questões os perpassam, tais como a influência materna e da família extensa, a valorização da instituição familiar, a ênfase na provisão material e no vínculo biológico, a dificuldade diante da expressão espontânea do afeto, o conflito diante do papel real e ideal de pai na contemporaneidade. Além disso, a pesquisa ressaltou a atualidade da teoria winnicottiana, mostrando-se como um importante recurso para questões da contemporaneidade. No entanto, espera-se que este trabalho seja um incentivo, não só para pesquisas em Psicanálise, mas também nas mais diversas correntes do saber na busca de olhares plurais sobre a multifacetada relação entre a díade pai/ filha. Tais pesquisas viriam a contribuir também para novos estudos que utilizem a própria teoria winnicottiana, afinal, para esse autor, o indivíduo é ambiente e a "saúde mental é produto de um cuidado incessante que promove o crescimento emocional" (Winnicott, 1945/2000, p. 305).

\section{Referências}

Abram, J. (2000). A Linguagem de Winnicott. Rio de Janeiro: Revinter.

Aiello-Vaisberg, T. M. J. (2004). Ser e fazer: Enquadres diferenciados na clínica Winnicottiana. Aparecida, SP: Ideias e Letras.

Aiello-Vaisberg, T. M. J., \& Machado, M. C. L. (2005). $O$ gesto do sonhador brincante. Trabalho apresentado no Congresso Estados Gerais da Psicanálise, Rio de Janeiro, RJ.

Amazonas, M. C. L. A., \& Braga, M. G. R. (2006). Reflexões acerca das novas formas de parentalidade e suas possíveis vicissitudes culturais e subjetivas. Ágora, 9(2), 177-191. doi: 10.1590/ S1516-14982006000200002

Andrade, T. de M.; Moraes, D. E. B.; \& Ancona-Lopez, F. (2014). Problemas Psicológicos e Psicodinâmicos de crianças e adolescentes obesos: Relato de pesquisa. Psicologia: Ciência e Profissão, 34(1), 126141. doi: 10.1590/S1414-98932014000100010

Bauman, Z. (2004). Amor líquido: Sobre a fragilidade dos laços humanos. (C. A. Medeiros, Trad.). Rio de Janeiro, Zahar.

Bellak, L., \& Bellak, S. S. (1981). Teste de apercepção infantil: Com figuras de animais - CAT-A. (O. Mantovani, Trad.). São Paulo: Mestre Jou. (Trabalho original publicado em 1949).

Barbieri, V. (2015). A experiência materna de mulheres brasileiras, francesas e magrebinas e o desenvolvimento do Self infantil (Tese de livre docência). Faculdade de Filosofia, Ciências e Letras de Ribeirão Preto, Universidade de São Paulo.

Bomfim, I. H. F. B. (2015). Narrativas maternas: Um estudo transcultural com mães brasileiras e francesas (Tese de doutorado). Faculdade de Filosofia, Ciências e Letras de Ribeirão Preto - Universidade de São Paulo.

Corbin, A. (2008). História do corpo. Rio de Janeiro: Vozes.

Dias, E. O. (2003). A teoria do amadurecimento de D. W. Winnicott. Rio de Janeiro: Imago.

Dupuis, J. (1989). Em nome do pai: Uma história da paternidade. São Paulo: Martins Fontes.

Psico-USF, Bragança Paulista, v. 23, n. 2, p. 267-278, abr./jun. 2018 
Ferrari, M., \& Kaloustian, S. M. (2002). Introdução. Em Kaloustian, S. M. (Ed.) Família brasileira, a base de tudo (Vol. 2, pp. 11-15). UNICEF, São Paulo: Cortez.

Florentino, C. (2002). Um escuro poço: A memória enferma em Lavoura Arcaica, de Raduan Nassar. Em tese, 5, 215-222. Recuperado de http://150.164.100.248/poslit/08_publicacoes_ pgs/Em\%20Tese\%2005/24-Cristiano-Florentino. pdf

Freitas, W, de M. F., Silva, A. T. M. C., Coelho, E. A. C., Guedes, R. N., Lucena, K. D. T., \& Costa, A. P. T. (2009). Paternidade: Responsabilidade social do homem no papel de provedor. Revista de Saúde Pública, 43(1), 85-90. doi 10.1590/ S0034-89102009000100011

Freud, S. (1996). 22 $2^{\mathrm{a}}$. Conferencia: Algunas perspectivas sobre el desarrollo y la regresión. Conferencias de introducción al psicoanálisis. In Sigmund Freud: 15. Obras Completas. Buenos Aires, Argentina: Amorrortu. (Original publicado em 1916-1917).

Fulgencio, C. D. R. (2007). A presença do pai no processo de amadurecimento: Um estudo sobre Winnicott (Dissertação de mestrado). PUC-SP.

Girola, R. (2004). A Psicanálise cura? Uma introdução à teoria Psicanalítica. Aparecida, SP: Ideias e Letras.

Lobo, M. (2008). As condições de surgimento da mãe suficientemente boa. Revista Brasileira de Psicanálise, 42(4), 67-74. doi: 10.1590/1413-7372189590009

Motta, I. F. (2006). Orientação de pais, novas perspectivas no desenvolvimento de crianças e adolescentes (pp. 13-19). São Paulo: Casa do Psicólogo.

Oliveira, M. F., \& Camões. C. (2003). As crianças institucionalizadas: $\mathrm{O}$ outro lado da sociedade [Versão eletrônica]. Recuperado de http://www.psicologia. com.pt

Oliveira, M. C. F. A., Vieira, J. M., \& Barros, L. F. W. (2010). Composição dos domicílios e núcleos familiares brasileiros: Revelações da PNDS 2006. Trabalho apresentado no XVII Encontro Nacional Populacionais. Mimeo.

Piccinini, C. A., Silva, M. da R., Gonçalves, T. R., Lopes, R. de C. S, \& Tudge, J. (2012). Fathers' involvement during the baby's third month. Psicologia: Teoria e Pesquisa, 28(3), 303-314. doi: 10.1590/ S0102-37722012000300006
Rosa, C. D. (2011). O papel do pai no processo de desenvolvimento de Winnicott. Em E. O. Dias \& Z. Loparic, Z. (Eds.) (2011). Winnicott na Escola de São Paulo (pp. 257-303). São Paulo: D. W. W. Editorial.

Rohner, R. P. (1998). Father love and child development: History and current evidence. Current directions in psychological science, 7(5), 157-161. doi: 10.1111/1467-872

Romanelli, G. (2003). Paternidade em famílias de camadas médias. Estudos e pesquisas em psicologia, 3(2), 79-95. Recuperado de http://www.e-publicacoes.uerj.br/index.php/revispsi/article/ view $/ 7790 / 5638$

Roudinesco, E. (2003). A família em desordem. (A. Telles, Trad.). Rio de Janeiro: Jorge Zahar

Safra, G. (2005) A face estética do self: Teoria e clínica. São Paulo: Unimarco Ed.

Sander, M. A. (2002). The psychoanalytic method from an epistemological viewpoint. International Journal of Psychonalysis, 83, 491-505. doi: 10.1516/ EPM9-WQAV-5L37-X3T1

Silva, M. R., \& Piccinini, C. A. (2007) Sentimentos sobre a paternidade e o envolvimento paterno: um estudo qualitativo. Estud. psicol. (Campinas) 24(4). 24, n.4, 561-573: doi: 10.1590/S0103-166X2007000400015

Silva, M. R. S., Nunes, M. E., \& Ribeiro, J. P. (2014). A percepção dos pais frente ao seu envolvimento nas atividades com $\mathrm{O}(\mathrm{s})$ filho(s). Revista Gaúcha de Enfermagem, 35(1), 14-21. doi: 10.1590/1983-1447.2014.01.36602

Simas, S. (2009). Família no plural: O grande desafio das políticas sociais na contemporaneidade. Estudos Femininos, 17(1), 277-278. doi: 10.1590/ S0104-026X2009000100018

Singly, F. de. (2007). Sociologia da família contemporânea. Rio de Janeiro: Ed. FGV.

Tachibana, M., Ambrosio, F. F., Beaune,D., \& Vaisberg, T. M. J. A. (2014). O imaginário coletivo da equipe de enfermagem sobre a interrupção da gestação. Ágora: Estudos em Teoria Psicanalítica, 17(2), 285-297. doi: 10.1590/S1516-14982014000200009

Thorne, B. (1992). Feminism and the family: two decades of thought. Em B. Thorne \& M. Yalom (Eds.). Rethinking the Family: some feminist questions. Boston: Northweastern University Press. 
Winnicott, D. W. (1982). A criança e o seu mundo. (J. O. A. Abreu; V. Nobre, Trad.). Rio de Janeiro: Zahar. (Trabalho original publicado em 1955).

Winnicott, D. W. (1975). O brincar e a realidade (J. O. A. Abreu; V. Nobre, Trad.). Rio de Janeiro: Imago. (Trabalho original publicado em 1971).

Winnicott, D. W. (1990) Psicanálise do sentimento de culpa. Em O ambiente e os processos de maturação (pp. 19-30). (I. C. S. Ortiz, Trad.). Porto Alegre: Artes Médicas. (Trabalho original publicado em 1958).
Winnicott, D. W. (2000). Da pediatria à Psicanálise - Obras escolhidas (D. Bogomoletz, Trad.). Rio de Janeiro: Imago. (Trabalho original publicado em 1945).

Winnicott, D. W. (2005). A família e o desenvolvimento individual (M. B. Cipolla, Trad.). São Paulo: Martins Fontes. (Trabalho original publicado em 1960).

Recebido em: 18-02-2016 Reformulado em: 18-06-2016; 20-08-2016 Aprovado em: 16-11-2016

Sobre as autoras:

Andressa Pin Scaglia é psicóloga, graduada e mestre em Psicologia pela Faculdade de Filosofia, Ciências e Letras de Ribeirão Preto da Universidade de São Paulo (FFCLRP-USP), atua nas áreas de Saúde Mental, Atenção Psicossocial, Psicologia Clínica e atua na coordenação do Centro de Atenção Psicossocial Infantojuvenil (CAPSij) do município de Rio Claro-SP.

E-mail: andressascaglia@yahoo.com.br

Fernanda Kimie Tavares Mishima-Gomes é graduada em Psicologia, bacharelado e licenciatura, pela FFCLRP-USP, mestre e doutora pelo Programa de Pós-Graduação em Psicologia da FFCLRP-USP e, atualmente, é psicóloga da Universidade de São Paulo, campus Ribeirão Preto (FFCLRP-USP), responsável pelo Serviço de Triagem e Atendimento Infantil e Familiar da Clínica de Psicologia.

E-mail: ferkimie@yahoo.com.br

Valéria Barbieri é graduada em Psicologia (FFCLRP-USP), mestre e doutora em Psicologia Clínica IP-USP, realizou pós-doutorado na Universidade Paris Diderot - Paris 7, docente do Departamento de Psicologia da FFCLRP-USP e possui graduação livre docência em Psicodiagnóstico: Enfoque Avaliativo e Interventivo pela FFCLRP-USP.

E-mail: valeriab@ffclrp.usp.br

Contato com as autoras:

Universidade de São Paulo, Faculdade de Filosofia Ciências e Letras de Ribeirão Preto, Departamento de Psicologia e Educação.

Rua Clóvis Vieira, casa 34

Campus USP

Ribeirao Preto-SP, Brasil

CEP: 14040-901

Telefone: (16) 3602-3641 Ramal: 3819

URL da homepage: http:/ /ffclrp.usp.br 